\title{
Casas de Orates
}

\author{
Hugo Segawa
}

\begin{abstract}
A arquitetura de hospícios implantada no Brasil durante o século 19 correspon de a uma busca da modernização. Em sintonia com o surgimento desse programa arquitetônico na Europa e nos Estados Unidos, foi produto da compreensāo da questão da alienação mental como uma patologia passível de tratamento e, por conseguinte, da possibilidade de definir um espaço específico para essa finalidade. O trabalho busca demonstrar a trajetória dessa preocupaçāo no Brasil mediante a constataçāo do surgimento de hospícios no Rio de Janeiro, Recife, Porto Alegre, Belém e São Paulo, caracterizando um programa de amplitude até hoje pouco esclarecido.
\end{abstract}

Abstract

The architecture of mental hospitals adopted in Brazil during the 19th century reveals a search for the modernization. This happened at the same time that architectural program was in progress in Europe and United States, as a result of the concept that mental illness has a pathology and can be medically handled, and, therefore, can define specifically an architectonic space for the activity. The investigation refers to the development of mental hospitals in Rio de Janeiro, Recife, Porto Alegre, Belém and Sāo Paulo, distinguishing a wide effort unknown until now.
Artigo extraido da Dissertaçāo de Mestrado "Construçāo de Ordens: um aspecto da Arquitetura no Brasil 1808-1930", apresentada em abril de 1988 .

Orientadora: Prota Dra Aracy A. Amaral. 
A Rebelião

Cerca de trinta pessoas ligaram-se ao barbeiro, redigiram e levaram uma representação à Câmara.

A Câmara recusou aceitá-la. declarando que a Casa Verde era uma instituição pública, e que a Ciência não podia ser emendada por votação administrativa, menos ainda por movimento de rua.

- Voltai ao trabalho, concluiu o presidente, é o conselho que vos damos.

Machado de Assis, em O Alienista

Casa Verde. no conto/novela O Alienista (datado de 1881/1882), é o imaginário hospital municipal de alienados de Itaguaí, criado e sob responsabilidade do Dr. Simão Bacamarte, em quem Machado de Assis - destilando toda sua fina ironia - personalizou a desconfiança sobre um saber médico capaz de diagnosticar anomalias mentais mediante observaçōes do comportamento cotidiano. Investido de uma autoridade e poder legitimados pela ciência, o Dr. Bacamarte num primeiro momento faz internar os ricos. os poderosos, os aproveitadores. os espertos e assim por diante. Com a formulação de uma "nova teoria" o alienista inverte o quadro: liberando os reclusos anteriores. condena para a Casa Verde os honestos, os justos. os trabalhadores, julgados como portadores de sintomas de anormalidade.

Interferindo na vida de quase toda a população, o $\mathrm{Dr}$ Bacamarte afinal chega a uma conclusão: o único que padecia de alguma patologia anormal era ele próprio. Libertando todos os seus pacientes, ele acaba sucumbindo, só, dentro de sua criação: o hospício.

Machado de Assis, no último quartel do século 19, vulgarizava para seus leitores um complexo tema cuja introdução, no Brasil, podemos situar simbolicamente no final da primeira metade do Oitocentos, com a criação do Hospício de D. Pedro II no Rio de Janeiro. Conviria situar um pouco a questão dos alienados. Se o dicionário é o repositório dos significados correntes. dos lugares comuns de uma epoca, vamos apelar para o Dictionnaire D'Hygiene Publique de Ambroise Tardieu, datado de meados do seculo 19. consultando o verbete:

Alienados - Entre as reformas modernas que interessam ao mais alto grau de humanidade, e que fazem a maior honra ao nosso tempo, é impossivel nāo situar em primeira linha a melhoria da sorte dos alienados. Confundidos, até os primeiros anos deste século, com os criminosos, relegados no fundo dos calabouços ou nas celas de algumas casas religiosas, eles eram deixados ao mais completo abandono. Hoje. graças aos esforços de médicos homens de bem, e à preocupação enfim demonstrada pelos poderes públicos. os alienados. colocados sob a proteção, às vezes excessiva da lei, encontram por toda parte a assistência que seu estado reclamava. [Tardieu 1862 1:53].

\section{A Psiquiatria no Rio de Janeiro do Século 19}

O louco, então, de indivíduo criminoso elevava-se para a categoria dos pacientes medicalizáveis, posto a sua nova condição de vítima de doença passível de terapia especifica, codificada pela nascente psiquiatria. Nem por isso, todavia, merecedor de menor controle por parte da sociedade:

De todas as moléstias a que o homem é sujeito nenhuma há cuja cura dependa mais do local em que é tratada do que a loucura... Sem o 
isolamento, a tranqüilidade, o silêncio, quando eles são precisos; sem as convenientes separações dos loucos em classes segundo o gênero e espécie de alienação mental; sem o trabalho, as distraçōes, a ventilação, os passeios, os banhos, as embarcações; sem meios próprios de efetuar tudo isso e conter sem barbaridade os furiosos no seu delírio, sujeitandoos docemente ao tratamento que Ihes pode ser útil; sem uma grande atenção e cuidado todos dedicados a esta classe de doentes é impossivel obter-se boas curas e com facilidade,

vaticinava o médico italiano Luiz Vicente de Simoni (1792-1881) na memória importância e necessidade da criação de um manicômio ou estabelecimento especial, para o tratamento dos alienados, publicado em 1839 e propugnando a criação de um estabelecimento dessa natureza no Rio de Janeiro [apud Machado et al. 1978: 379-80].

Essa preocupação por uma instituição especial manifestou-se pela primeira vez em 1830, num relatório da Comissão de Salubridade da Sociedade de Medicina do Rio de Janeiro e era reforçada por um artigo do médico J. F Sigaud, cinco anos depois - Reflexóes acerca do trânsito livre dos doidos pelas ruas da cidade do Rio de Janeiro, etc. - preconizando o enclausuramento dos alienados em decorrência dos inconvenientes e ameaças que eles poderiam representar em liberdade pelas ruas [Moreira 1905:54 e Machado et al. 1978: 377].

Nesses passos, "coube à medicina social a tarefa de isolar preventivamente o louco com o objetivo de reduzir o perigo e impossibilitar o efeito destrutivo que ela viu caracterizada em sua doença. Nasce assim. no Brasil dos meados do século 19, não uma 'psiquiatria preventiva' mas a psiquiatria como instrumento de prevenção" [Machado et al. 1978: 380].

Moreira de Azevedo [1969 1: 473], em sua descrição do Hospício de D. Pedro II, assinalava a existência das "estátuas dos sábios Esquirol e Pinel" no vestíbulo principal do estabelecimento. O escultor alemão Pettrich, ao executar essas duas imagens entre 1842 e 1856 (periodo em que esteve ativo no Rio de Janeiro), fazia testemunhar o reconhecimento das autoridades cariocas sobre a importância e a inspiração emanada pelo trabalho dos franceses Philippe Pinel (1745-1826) e seu seguidor Jean Etienne-Dominique Esquirol (17721840), virtuais criadores da psiquiatria moderna. Assim, o Brasil ingressava no quadro das nações preocupadas com seus alienados preiteando os idealizadores de uma nova norma médica/social e materializando o principal instrumento terapêutico formulado sobretudo por Esquirol a partir da segunda metade do 19: o hospício.

\section{O Hospício de D. Pedro II}

A sagraçāo e coroaçāo de D. Pedro II em 1841, ensejou também a criação do estabelecimento que levou seu nome:

um hospital destinado privativamente para tratamento de alienados com a denominação de Hospicio de D. Pedro ll o qual ficará anexo ao Hospital da Santa Casa de Misericórdia desta Corte, debaixo de minha imperial proteção...

rezava o decreto de 18 de julho [apud Azevedo 1969 1: 470].

Projetado pelo tenente-coronel português José Domingos Monteiro, com modificações posteriores executadas por José Maria Jacinto Rebello (1821-1871) e 
o pórtico principal desenhado pelo engenheiro militar Joaquim Candido Guillobel (1787-1859), as obras do Hospício de D. Pedro Il começaram em 1842 e o início do seu funcionamento data de 1852.

Qual teria sido o princípio de organizaçāo do programa do hospicio? A regulamentação francesa de 18 de dezembro de 1839 (derivada da lei sobre os alienados de 30 de junho de 1838) oferece algumas referências:

$\left.1^{\circ}\right)$ Que o estabelecimento não ofereça nenhuma causa de insalubridade, tanto para os que estão dentro como fora. e que esteja situado de maneira que os alienados não sejam incomodados por uma vizinhança barulhenta ou capaz de agitá-los;

$\left.2^{\circ}\right)$ que possa ser suprido em todo o tempo de água de boa qualidade e em quantidade suficiente;

$3^{\circ}$ ) que pela disposição das dependências, permita separar completamente os sexos, as crianças e os meia-idades; de estabelecer uma classificação regular entre os convalescentes, os doentes pacíficos e aqueles que sāo agitados; de separar igualmente os alienados epilépticos:

$\left.4^{\circ}\right)$ que os estabelecimentos contenham locais particulares para os alienados atingidos por doenças acidentais e por aqueles que têm hábitos de desonestidade;

$\left.5^{\circ}\right)$ que todas as precauçōes sejam tomadas, seja nas construções, seja na fixação do número de guardas para assegurar o serviço e a vigilância do estabelecimento.

Estas prescrições resumem perfeitamente as principais condições de salubridade e de ordenaçāo interior que se deve impor aos estabelecimentos públicos ou privados consagrados ao tratamento de alienados, sentenciava Tardieu [1862-1:55].

O Hospício de D. Pedro II foi construído na praia Vermelha, e

... é admiravelmente situado: afastado do centro mais povoado. localizase ao sul da baía de Botatogo que. dominando vasta paisagem e tendo à sua volta grande extensāo de terreno a ele pertencente. faz com que realize perfeitamente as condições necessárias para um completo isolamento... Não é preciso dizer que o arquiteto que fez este hospício tomou como modelo os estabelecimentos análogos da Europa; ele somente fez a adaptação ao clima, planejando assim compartimentos maiores, tetos mais altos, e não poupando as despesas necessárias à sua construção. ele construiu um edifício suntuoso e digno de admiração.

exultava o médico Joäo Carlos Teixeira Brandāo em 1884 [apud Machado et al. 1978: 452].

Como todos os espaços hospitalares destinados ao isolamento e à terapia, o Hospicio de D. Pedro II situou-se distante dos aglomerados significativos. Construiu-se um suntuoso palácio, que só perdia, em porte. ao Hospital da Santa Casa da Misericórdia. Hospício e hospital projetados pelo mesmo engenheiro, o tenente-coronel Domingos Monteiro, inegavelmente conhecedor de arquitetura hospitalar européia. O grande volume, conformando uma extensa testada simetricamente ordenada por um pórtico neoclássico (desenhado por Joaquim Candido Guillobel). dominando o horizonte praiano, era soluçāo corrente nos hospitais marítimos ou fluviais europeus (aliás, adotada também para penitenciárias). 
A edificação, em dois pavimentos, tinha o seu eixo de simetria marcado pela capela, simetria demarcadora da fronteira entre a ala ocupada pelos homens e pelas mulheres, cada qual abrigando uma organizaçāo interna hierarquizada: primeira classe com quartos individuais, segunda classe com quartos compartilhados e terceira classe para indigentes e enfermarias gerais para 15 pessoas; divisão por categoria de pensionistas, internos tranqüilos, agitados, indigentes, limpos, imundos e afetados por moléstias contagiosas - conforme rezavam os estatutos do hospício [Machado et al. 1978: 433]. Ordenaçāo disciplinar, compartimentaçāo em inúmeros cubículos em comunicaçāo mediante longos corredores, contornando pátios internos à maneira de celas conventuais - referências espaciais marcantes em toda a arquitetura hospitalar até o final do século 19.

\section{Arquitetura "Inadequada"}

Enquanto esquema geral, o Hospício de D. Pedro Il obedeceu a alguns principios disseminados até o ınício do século 20. O Traité D'Architecture de Louis Cloquet. de 1900, observava a recomendação de situar os nospicios "no campo" mas "próximos à cidade" e näo em seu interior, distante "das agitaçōes populares"

Fora da cidade há vantagem de poder-se criar estabelecimentos agricolas e, para os alienados tranqüilos, de thes poder oferecer locais que agradam à vista [Cloquet 1900. 4: 507].

uma reminiscência de antigos tratamentos que contrapunham o espaço da natureza à artificialidade do hospital para a terapia da loucura: "a viagem. o repouso, o passeio, o retiro, o corte com o mundo vão e artificial da cidade" [Foucault 1986: 120-1]. Na ordenaçāo interna, Cloquet era taxativo:

Dentro dos estabelecımentos deste gènero e necessário dispersar os doentes. A disposição radial aqui é inútil; a vigilâncla central é desnecessária; a vigilância se faz sobretudo dentro das salas e dos dormitórios. As edificaçōes têm formas retangulares alongadas. formas essencialmente favoráveis à classificação dos doentes [Cloquet 1900 4: 506-7].

A questão da classificação era um componente forte na prática psiquiátrıca do Hospício de D. Pedro ll e uma das maiores fontes de crítica à sua arquitetura:

É forçoso confessar as numerosas imperfeiçōes que se notam no plano arquitetônico do Hospicio de D. Pedro II: ai a arte esqueceu a ciência: sua construção é imponente e monumental, porem peca pelo lado científico de sua missão.

sentenciava o Dr. Gustavo Balduino de Moura e Camera. diretor do estabelecimento em seu relatório de 1877-78 [apud Machado et al. 1978: 452]. O tipo de compartımentaçāo das dependências e organızação das circulações nāo se compatibilizariam com os critérios de classificaçāo adotados pela instituição (nem todos necessariamente segundo modalidades médicas, propriamente dito como vimos há pouco).

Na realidade, o prédio do Hospicio de $D$. Pedro II foi vítima de seu próprio pioneirismo: criado quase que simultaneamente às instituições equivalentes na Europa ou, pelo menos, pouco em seguida à regulamentação francesa acerca dos estabelecimentos dessa natureza - inspirado em modelos teóricos formulados por Esquirol e outros, a transposição desse modelo para o espaço arquitetônıco não respondeu as expectatıvas, obedecidos os pressupostos 
teóricos condicionadores do projeto de arquitetura. A arquitetura também é uma experimentação - tanto quanto foi a psiquiatria no século 19. Mas se a aferição de dados e formulação de hipóteses científicas obedecem a uma dinâmica volátil, tal velocidade não é compartilhada pelas construções -e, em muitos casos, a arquitetura espelha uma realidade já anacrônica em relação ao desenvolvimento das idéias. O Hospício de D. Pedro II foi construído segundo modelos arquitetônicos correntes na época. Do ponto de vista estilístico, a solução neoclássica configurava, no Rio de Janeiro de meados do Oitocentos, um padrāo avançado. Todavia, a organizaçāo das plantas e os volumes decorrentes, também de disciplina neoclássica em sua simetria rígida e modular, nāo mais se compatibilizavam com pressupostos funcionais ordenados pela medicalização do espaço hospitalar em processamento desde o século 18 na Europa. A crítica à monumentalidade do Hospício de D. Pedro li era superficial. pois tratava-se de um projeto arquitetônico cujo equívoco não estava propriamente na riqueza de sua ornamentaçāo neoclássica ou volume edificado afinal, um belo edifício demonstrando a inserção do país no restrito círculo das naçōes "civilizadas" preocupadas com seus alienados. Seu problema estava na organização do espaço, pouco propício à gestão do poder médico e do refinamento das formas de controle mediante a classificação - uma ordenação que obstaculizava o aperfeiçoamento das formas de arbitrariedade sobre os doentes travestidas em saber psiquiátrico.

\section{Arquiteturas de Hospicios no Brasil}

Nas provincias, o paulatino reconhecimento da patologia distinta dos alienados parece aflorar a partir dos anos 1860 . certamente esclarecido pela existência de um estabelecimento modelar a eles destinado na Corte. Mas talvez seja prematuro afirmar que esse reconhecimento tivesse natureza psiquiatrica. Em toda parte, sem exceção, os alienados internados em instituições não-carcerárias constituíam uma subpopulação a vagar pelas santas casas de misericórida. Correto seria encarar esse internamento como uma forma de subtrair do ambiente social esses individuos, sem necessariamente acomodá-los em locais clínicos.

No conjunto de inıcıativas registradas por Juliano Moreira nas várias províncias. boa parte das arquiteturas que abrigaram hospicios nāo mais eram que adaptações de edificaçōes preexistentes. Depreende-se da leitura do trabalho do alienista que, até 1905, quatro províncias ou estados haviam construído edificações para hospícios.

Em Pernambuco, o Hospital da Visitação de Santa Isabel foi aberto em 1864 nas instalações da Santa Casa de Misericórdia de Olinda, numa adaptação mal sucedida. Um edifício específico para a finalidade foi inaugurado em 1883 no antigo sítio conhecido como Tamarineira [Coêlho 1954: 7-13 e passim]. Juliano Moreira, acerca do edifício, observava que

Como construção tem defeitos que bem poderiam ser evitados na época em que foi executado se o arquiteto tivesse em vista o melhor modelo a imitar. Mas nem sempre a opinião do alienista é convenientemente acatada por ocasião de ser planejado um manicômio [Moreira 1905: 87].

O Rio Grande do Sul inaugurou em 1884 o Hospício São Pedro, construido às expensas da província, não obstante apenas metade do estabelecimento tenha sido concluído - seis pavilhões - até a data da observação do alienista. 
O Pará construiu e inaugurou seu hospício no período republicano. Aberto em 1892 com o patrocínio do governo, o manicômio belenense em seus primeiros anos de atividade acusou um alto índice de mortalidade de internos, ensejando uma rigorosa reformulação das condiçōes sanitárias de suas dependências, bem como a reorganização administrativa e terapêutica no tratamento aos doentes [Moreira 1906: 429-32].

A criação do Hospício e Colônias de Juquery em São Paulo, na primeira década da República, constitui a mais significativa iniciativa no campo da arquitetura psiquiátrica no período de nosso interesse e no qual vamos nos deter com mais cuidado adiante.

No Paraná, o prédio da Penitenciária do Ahú, construido na primeira década do século 20 , originalmente deveria abrigar um hospício de alienados patrocinado pela Santa Casa de Misericórdia. Jamais funcionou como tal [Britto 1926: 182 e passim]. Essa metamorfose demonstra a inconsistência de um desenho arquitetônico que, adaptável a diferentes solicitaçōes, nāo servirı satisfatorımente a nenhuma delas.

\section{O Juquery em São Paulo}

A abertura do primeiro manicômio de São Paulo decorreu da recusa da Santa Casa de Misericórdia em se responsabilizar por estabelecimento dessa natureza e sua criaçāo foi simultânea à inauguração do Hospício de D. Pedro ll do Rio de Janeiro: em 1852, uma casa na rua de São Joāo (esquina com a rua Aurora) abrigaria nove internos, "alguns criminosos" Se os hospícios eram contemporâneos entre si, qualquer comparaçāo entre as duas instalaçōes seria ridícula. Abrigado em edifício especialmente construido para a finalidade, o hospício da Corte nāo amargou as vicissitudes de se acomodar em improviso permanente como se sucedeu com a casa paulista até o final do século 19.

Tanto quanto as congêneres que se fundaram nas demaıs cidades das províncias brasileiras, o hospício de São Paulo não se compatibllizava com os preceitos de tratamento psiquiátrico preconizado pelos alienistas. Criticado pelos especialistas, condenado pelos sanitaristas, esses hospícios não passavam de derivações de cárceres ou mero depósito de presos, diferenciados apenas pelo comportamento fora dos padrōes de seus internos - os "loucos"

O quadro de atendimento aos alienados deveria ser assustador para as autoridades e para a população. A antevisão da breve convivència que o hospício de São Paulo, na várzea do Tamanduateí, teria com a cidade. constatada a expansāo urbana em processo no final do século 19. em muito deve ter sensibilizado o poder público, além das seqüelas de um severamente criticado atendimento precário a alienados promovido por um estabelecimento mantido pelo Estado. Não seria casual a imediata intervenção do novo regime republicano na questão. A lei no 15 de 11 de novembro de 1891 criava três asilos agrícolas de alienados em Sorocaba, Itapetininga e Guaratinguetá. A portaria no 73 de 26 de abril do ano seguinte referia-se à autorização para construçāo de um "Asylo Agrícola de Alienados" em Sāo Paulo, cujo projeto era do arquiteto Emile Olivier [RSASP 1892: 26]. Iniciativas desordenadas que encontrariam seu condutor em Francisco Franco da Rocha (1865-1933). médico formado no Rio de Janeiro em 1890 e cujo currículo, registrando estágıos em instituiçōes alienistas na Corte. o credenciava a conduzir a política de assistência aos alienados a partir de 1892. 
À questão da descentralização do atendimento preconizada na lei de 1891 , Franco da Rocha procurou e conseguiu demonstrar aos poderes públicos que havia. conveniência em não tornar efetiva a referida autorizaçāo; que o Estado necessitava criar na capital ou perto, um hospício central, modelo, construido segundo as prescriçōes da psiquiatria moderna, em pavilhōes isolados; que a este dever-se-ia anexar uma colônia modesta, barata não distante dele a fim de ai ser ensaiado o sistema de open-door [Moreira 1905: 86].

Coube a Franco da Rocha. Theodoro Sampaio e A. Loefgren participar da comıssão para a escoiha do local para a instalação do hospício dos alienados [RSISP ! 893:XXXIII]. Quais teriam sido os critérios de seleção?

1 №̃o ser muito perło da cidade, para que em breve não seja o edificio alcançado pelo desenvolvimento que a mesma possa tomar.

2- Ter área suficiente não só para as edificaçôes necessárias, como também para a aplicação agricola dos asilados.

3o Ser de fácil acesso, o que não só convirá à construçāo como à fiscalização do estabelecimento.

4ำ Ter abundância de água para todos os misteres

$5^{\circ}$ Não apresentar dificuldade para o transporte dos materiais de modo a encarecề-los.

$6^{\circ}$ Não serem muito caros os terrenos [RSISP 1894: [X].

Três foram as alternativas estudadas na ocasiāo: na Moóca - local prontamente descartado pela proxımidade com a cidade e näo oferecer água com facılidade; - em Santana, próximo à serra da Cantareira - em terreno devoluto, acessivel pela Tramway da Cantareira, a 7 quilômetros da cidade ("o que faz supor que nem em 50 anos seja povoado e servida pelo sistema de abastecimento de água da Companhia Cantareira de Águas e Esgotos com o reservatório da região; - e em Juquery - em regiāo norte da capital, além Santana. que foi contemplada para receber o hospício.

Juquery, nome do rio e da estaçāo da antiga São Paulo Railway. situava-se a 55 minutos pela estrada de ferro, servida por 14 trens diários. O rio proporcionava água e um salto próximo poderia dotar o hospital de energia elétrica. A proximidade com Caieiras, regiāo fornecedora de cal e pedra, tacilitaria : acesso a materiais de construçāo bruta. Ao terreno devoluto se optou pela aquisição de terrenos da ordem de 150 hectares onde se impiantou o sistema manicomial concebido por Franco da Rocha

O médico paulista não encontrou de imediato a solução arquitetônica adequada compativel com seus anseios: em 1892, um primeiro projeto foi recusado, "nāo tendo o engenheiro arquiteto bem compreendido os desejos do alienista" e uma segunda iniciativa, desenvolvida pela Superintendência de Obras Públicas. também não agradou a Franco da Rocha.

Fol arquiteto de tāo útil instituto o dr. Ramos de Azevedo que inteligente e ilustrado soube compreender o que devia fazer para realizar o sistema de manicömio que o alienista Franco da Rocha propusera ao Governo. Disposiçäo de pavilhões, número de cômodos, etc., tudo felto de acordo entre o arquite to e o alienista [Moreira 1905: 87).

superando a dicolomia entre o arquiteto e o médico. 
O asilo-colônia de Juquery, como se chamou o hospício hoje no município de Franco da Rocha, era o corolário de dois objetivos perseguidos pelo alienista:

I - Assegurar a esses infelizes [os alienados] um tratamento humanitário, dando-Ihes relativo bem-estar quando de todo não seja possivel obterIhes a cura por meio de medicações conhecidas;

"l - Realizar esse beneficio com a maior economia possivel. isto é. auxiliar a manutenção dos doentes com o seu próprio trabalho e assim alviar a despesa que atualmente é suportada pela comunhão social [Rocha 1906: 18].

A estrutura do asilo-colônia tinha claro amparo na experiência internacional e sua concepção obedecia aos ditames então predominantes na clínica psiquiátrıca. Os diversos pavilhōes de tratamento abrigavam pacientes merecedores de alguma vigilância e observação ("alienados com tendências eróticas, débeis mentais" semidementes) sem, no entanto, demandar células isoladas. Estas se destinavam aos ditos "agitados" cujo pavilhāo, "de isolamento" era organizado em rotunda. segundo princípio em panóptico e equipado com toda sorte de recursos "clinicos" como se pôde aferır na descrição $(\bullet$ Ramos de Azevedo [1896: 25-9]. A este conjunto. dotado de infra-estrutura geral (administração, lavanderia. cozinha. etc.), denominou-se asilo central de tratamento.

O regime de upen-door, adotado em graduaçōes distintas para as colônıas agricolas anexas ao asilo central e à fazenda. em oposição ao tratamento em asilo fechado. isolando seus internos do meio, propiciava maior grau de liberdade aos alienados ditos "tranqüilos" julgados não-perigosos e passiveis de conviverem com o ambiente organizado segundo o trabalho agrícola, voltado para a produçāo de gêneros para o hospício, baseado no princípio da não-ociosidade (de cunho moralista) aplicado como terapia e como recurso de retorno produtivo ao sistema. O asilo-colônia - cuja referência internacional era o de Alt-Scherbił̌z. perto de Leipzig. Alemanha - constituia uma solução de implantaçāo barata e rápıda. não pressupondo intra-estrutura maıs sofisiıcada que pequenos pavilhões, como na segunda colônıa em Juquery: uma para cozinha e depositos e cınco para entermarıa. totalizando seis edificaçōes de porte modesto.

Ainda na estruiura concebida por Franco da Rocha previa-se o chamado "sistema alemão" ou a assistência proporcionada pelo convivio do alıenado com família habitante no perímetro do hospital-colônia e a assistência familiar desenvolvida completamente fora do Instituto, mas na vila de Juquery, à maneira da experiência desenvolvida por Konrad Alt nos limites do hospital-colônia de Uchtspringe, perto de Hannover, e na pequena cidade de Gaddelegen, com aldeōes de confiança [Moreira 1910, Rocha 1906/1910/1912]. Na realidade. Juquery era uma pequena cidade governada pelo médico-chefe com uma populaçāo virtualmente condenada em sua liberdade.

\section{A Decadência de um Sistema}

Na prımeıra década do sécuio 20, já se aceitava entre os alienistas a inserção do nospital psiquiátrico na área urbana:

Deverá ser urbano o hospital, porque o individuo que enlouquece tem tanto direito a socorros urgentes quanto o que fratura a perna, ou recebe uma bala...[e]...as grandes cidades têm tanto maior necessidade de uma hospitalização imediata dos alienados quanto maior ou mais densa sua populaçäo. 
afirmava Juliano Moreira em 1910 [1910: 376], concebendo um sistema no qual o hospital urbano seria complementado por uma linha-auxiliar de colônias. O então diretor do Hospital Nacional dos Alienados também justificava dessa maneira o papel de seu hospício no Rio de Janeiro, construido segundo outros critérios e assumindo um novo lugar no quadro de assistência aos alienados:

O antigo asilo fechado tende a desaparecer, sendo transformado em hospital urbano para tratamento imediato dos casos agudos de alienação mental. Por isso, não thes é mais permitida a antiga feição de cárcere com as suas pesadas grades e correlatos horrores [Moreira 1910: 375].

Moreira ainda vislumbrava nova características para as dependências asilares:

As salas do hospital urbano para doentes do cérebro. de mais em mais se assemelham as do hospital para outras doenças...[e]...no hospital e na colônia há sempre a preocupação de afastar tudo o que possa lembrar caserna, ou casa de detenção. Não há mais aquelas divisões simetricamente dispostas. uniformemente arrumadas. nem aqueles altos muros. separando seções, nem aquelas grossas grades que tanto afeiavam as janelas e irritavam os doentes [Moreira, 1910: 376, 379].

Franco da Rocha não se posicionava de maneira tão otimista:

A liberdade, quando se trata de doidos, não pode deixar de ser mui relativa. A preocupação de evitar o aspecto de prisão. de dar ao asilo aparência de habitação comum. tem sido um pouquinho exagerada por alguns alienistas. O caráter de prisão é. entretanto. inevitável: quando não estiver nos muros e janelas gradeadas. estará no regime. no regulamento um tanto severo, indispensável para um grande numero de doentes [Rocha 1912: 6-8].

O alienista situava a outra dimensão do hospício: não a prisão materializada com "altos muros, grossas paredes" mas a prisão configurada pelo exercício do poder do médico, o confinamento e o tratamento preconizado no "regime, no regulamento" Normas voltadas para a recuperaçāo do indivíduo: o indivíduo criminoso, na penitenciária, submetido a uma ordem por sua "regeneração moral"; o louco, no manicômio, submetido ao regime por sua "regeneração mental" Duas tentativas de reinserção dos cidadãos fora-dos-padrōes no tecido social ou recurso institucionalizado de suprimir esses individuos do convívio da sociedade? É fato que a psiquiatria de Juliano Moreira e Franco da Rocha rumou para a antipsiquiatria. no conceito e no fato. A medicalização do alienado transformou-se. no Hospício de D. Pedro II como no Juquery, numa grande contradição. Os grandes hospícios do século transformaram-se ao longo do século $20 \mathrm{em}$ "elefantes brancos" problemas maiores que as soluçōes alvitradas em suas concepçōes originais. O procedimento científico reclamou a competência exclusiva do médico na abordagem da questāo. O sentimento humanitário, a filantropia presente na gênese do hospital complementou o quadro: curar ou apenas abrigar e assistir o louco?

O hospício foi um programa arquitetônico que se consubstanciou a partir de requerimentos ordenados pela ordem médica e até foi contemplado com um receituário arquitetônico sistematizado em manuais como os de Cloquet ou de Guadet. Ramos de Azevedo procurou atender às prescriçōes passadas por Franco da Rocha. E o arquiteto paulista seguiu. de modo geral. os últimos padrōes então vigentes na arquitetura hospitalar européia do final do século 19: sistema pavilhonar. inspirado no princípio do isolamento, segundo um esforço classificatório próprio do repertório psiquiátrico da época. Aliás, foi essa fúria classificatória que fez os médicos condenarem a não-funcionalidade 
do Hospício de D. Pedro II. Vontade de classificar intensa a ponto de se excluir da morfologia arquitetônica do hospício a soluçāo em panopticon, como asseverava Cloquet em suas recomendaçōes: "vigilância central é desnecessária... é necessário dispersar os doentes... [as edificaçōes têm] formas essencialmente favoráveis à classificação dos doentes" Dispersão resultante de um modelo psiquiátrico em busca de um refinamento na identificação de patologias novas, criar "verdades médicas" cuja sistematizaçāo arquitetura alguma é capaz de abrigar. Para formulação teórica como aquela desenvolvida pela psiquiatria do médico paulista e no contexto em que foi aplicado, espaço algum corresponderia a um rebatimento arquitetônico adequado. Não há arquiteturas que possam resistir a "verdades" como aquelas idealizadas pelo machadiano Dr. Simāo Bacamarte.

\section{Bibliografia}

ASSIS, Machado de. O alienista. São Paulo: Cultrix, 1961.

AZEVEDO, Manuel Duarte Moreira de. O Rio de Janeiro: sua história, monumentos, homens notáveis, usos e curiosidades. 3 ed. Rio de Janeiro: Brasiliana. 1969. 2 v.

AZEVEDO, Francisco de Paula. [Relatório de Ramos de Azevedo sobre a construção do manicômio do Juquery]. In: RELATÓRIO apresentado ao Sr. Dr. Presidente do Estado de S. Paulo em 30 de março de 1896 pelo Secretario de Estado dos Negócios do Interior e Instruçảo Pública Alfredo Pujol. Sảo Paulo, Typographia do "Diario Official" 1896.

BRITTO, Lemos. Os systemas penitenciarios do Brasil. Rio de Janeiro: Imprensa Nacional, 1924 (v. 1), 1925 (v. 2), 1926 (v. 3).

CLOQUET, L. Traité D'Architecture. Paris/Liège: Librairie Polytechnique/Ch. Béranger, 1900. v. 4.

COÊLHO FILHO, Heronides. A psiquiatria em Pernambuco. Recife: s.ed., 1954.

CUNHA, Maria Clementina Pereira. O espelho do mundo: Juquery, a história de um asilo. Rio de Janeiro: Paz e Terra, 1986.

FOUCAULT, Michel. Microfisica do poder. 6 ed., Rio de Janeiro: Graal. 1986.

História da loucura na ldade Clássica. Sảo Paulo, Perspectiva. 1978.

GOFFMAN, Erving. Manicômios, prisões e conventos. São Paulo: Perspectiva, 1974.

GUADET, Julien. Éléments et théorie de l'architecture. 4. ed., Paris: Librairie de la Construction Moderne, s.d., 4 v.

MACHADO, Roberto et al. Dalnjaçâo da norma: medicina social e constituiçāo da psiquiatria no Brasil. Rio de Janeiro: Graal. 1978.

MARTINS, Antônio Egídio. São Paulo antigo. 2 ed.. São Paulo: Conselho Estadual de Cultura, 1973 [org. Fernando Góes: pref. e notas Byron Gaspar].

MOREIRA, Juliano. Quaes os melhores meios de assistencia aos alienados? Archivos de psychiatria, neuro logia e medicina legal, Rio de Janeiro: v. 6. n. 1/2, p. 373-96. 1910.

Assistencia a alienados no Pará e no Rio Grande do Sul. Archivos brasileiros de psychiatria, neurologia e sciencias affins. Rio de Janeiro, v. 2, n. 1, p. 429-35, 1906

. Notícia sobre a evoluçāo da assistência a alienados no Brasil. Archivos brasileiros de psychiatria, neurologia e sciencias affins. Rio de Janeiro, v. 1, n. 1 , p. 2-101, 1905.

RELATÓRIO apresentado ao Sr. Presidente do Estado de S. Paulo em 15 de março de 1897 pelo Secretario de Estado dos Negócios do Interior Antonio Dino da Costa Bueno. São Paulo, Typographia do "Diário Official" 1897 [RSISP]. 
RELATÓRIO apresentado ao Sr. Dr. Presidente do Estado de S. Paulo em 30 de março de 1896 pelo Secretário de Estado dos Negocios do Interior e Instruçāo Pública Alfredo Pujol. São Paulo, Typographia do "Diario Official" 1896 [RSISP].

RELATÓRIO apresentado ao Sr. Dr. Presidente do Estado de Sảo Paulo pelo Dr. Cesario Motta Junior Secretario de Estado dos Negócios do Interior em 28 de março de 1894. São Paulo, Typographia a vapor de Vanorden \& Comp., 1894 [RSISP].

RELATÓRIO apresentado ao Sr. Dr. Presidente do Estado de São Paulo pelo Dr. Cesario Motta Junior Secretario dos Negócios do Interior a 7 de abril de 1893. São Paulo, Typ. a vapor de Vanorden \& Comp., 1893 [RSISP].

RELATÓRIO da Secretaria de Estado dos Negócios das Obras Públicas apresentado ao Exmo. Snr. Dr. Carlos Barbosa Gonçalves Presidente do Estado do Rio Grande do Sul pelo Secretario do Estado Candido José de Godoy em 27 de agosto de 1909. Porto Alegre, Officinas Graphicas da "Livraria Globo" 1909 [RSOPRGS].

ROCHA. Francisco Franco da. Hospicio e Colonnias de Juquery: vinte annos de assistência aos alienados em São Paulo. São Paulo, s.ed..1912.

Assistência familiar aos alienados em S. Paulo. Archivos brasileiros de psychiatria, neurologia e sciencias affins. Rio de Janeiro, v. 2. n. 1, p. 18-29, 1906

Assistëncia familiar aos insanos em S. Paulo. Archıvos brasileiros de psychiatria, neurologia e medicina legal. Rio de Janeiro, v. 6. n. 1/2. p. 397-402, 1910.

RSISP - ver RELATÓRIO.

TARDIEU, Ambroise. Dictionnaire d'hygiene publique et de salubrité ou repertoire de toutes les questions relatives a la santé publique, considérées dans leurs rapports avec les subsistences, les épidémies, les professions, les établissements et institutions d'hygiene et de salubrité, complété par le texte de lois, décrets, arrétés, ordonnances et instructions qui s'y rattachent. 10. ed. Paris, J.-B. Baillière et Fils, 1862. 2v.

TOLLET, Casemir. Les édifices hospitaliers depuis leur origine jusqu'à nos jours. 10 ed. Paris, s.ed., 1892.

VIANNA, Arthur. As epidemias no Pará. Pará, Diário Oficial. 1906. 